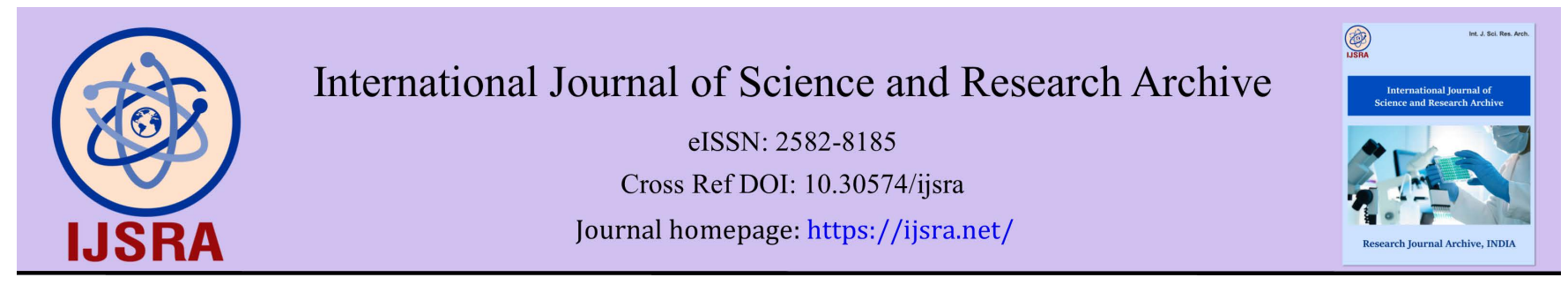

(RESEARCH ARTICLE)

\title{
Awareness and attitude of TB amongst undergraduates at the Rivers State University
}

\author{
Briggs NCT ${ }^{1}$, Eli $S{ }^{2,}{ }^{*}$, Nnoka VN ${ }^{3}$, Tee GP ${ }^{4}$, Wekere FCC ${ }^{1}$, Emeghara G ${ }^{4}$, Daka IR ${ }^{3}$ and Iyama AC 5 \\ ${ }^{1}$ Department of Community Medicine, Rivers State University. \\ ${ }^{2}$ Mother, Baby and Adolescent Care Global Foundation. \\ ${ }^{3}$ Department of Pharmacology, Rivers State University. \\ ${ }^{4}$ Department of Human Physiology, Rivers State University. \\ ${ }^{5}$ Department of Surgery, Rivers State University Teaching Hospital.
}

International Journal of Science and Research Archive, 2021, 04(01), 179-184

Publication history: Received on 07 November 2021; revised on 18 December 2021; accepted on 20 December 2021

Article DOI: https://doi.org/10.30574/ijsra.2021.4.1.0195

\begin{abstract}
Background: Creating awareness of TB amongst undergraduates of institutions of higher learning cannot be over emphasized. Health care delivery can be disseminated outside the walls of the hospital indirectly through undergraduates of higher learning by providing relevant information about disease condition, in this scenario TB in focus.
\end{abstract}

Aim:To determine the awareness and attitude ofTB amongst undergraduates at the Rivers State University.

Method:This was a cross-sectional study of 311 undergraduates at the Rivers State University. Permission to conduct the study was granted by the Provost of the College of Medicine, Rivers State University. Informed consent was obtained from the respondents. The data collected was analysed using SPSS version 25.

Results:Three hundred and eleven respondents participated in the study. There were $186(60 \%)$ males and 125 (40\%) females. The mean age was 24years; 285(91.6\%) were aware of TB; 251(80.7\%) of relations of respondents had open TB of which 40 (12.9\%) were treated;36 (11.5\%)had contact tracing for TB, while 172 (55.3\%) were aware of Direct Observe Therapy (DOT) for the treatment of TB.

Conclusion: The study revealed that the awareness of TB amongst undergraduates at Rivers State University was $91.6 \% ; 80.7 \%$ of the relatives of the respondents of the undergraduates had open TB of which only $12.9 \%$ were treated and $11.5 \%$ had contact tracing; $55.3 \%$ were aware of DOT. There is need to encourage persons with TB to receive treatment.

Keywords: Awareness; Attitude; Undergraduate; TB; Rivers State University

\section{Introduction}

Myriad of communities in Nigeria are endemic with Tuberculosis (TB) which is of public health concern locally and globally [1]. Stepping up surveillance and awareness in communities is a proactive strategy to manage the disease condition taking into consideration that Nigeria is the $7^{\text {th }}$ high burden TB country in the world $[1,2]$.

\footnotetext{
${ }^{*}$ Corresponding author: Eli S

Mother, Baby and Adolescent Care Global Foundation.
}

Copyright (@ 2021 Author(s) retain the copyright of this article. This article is published under the terms of the Creative Commons Attribution Liscense 4.0. 
Literature has shown that the awareness of TB is very important parameter to ascertain the order to provide baseline data to assist the decision makers to plan for and deliver an effective TB control programme [3-6.7-9]. This is in line with the World Health Organization call for increase campaigns on the awareness of tuberculosis [2].

Data earlier published from developing countries have shown that delayed care of TB is greatly linked to patient's demographic characteristics, knowledge of tuberculosis and traditional beliefs and the use of multiple alternative traditional care and fear of stigmatization, thus the reason for this study -'To determine the awareness and attitude of TB amongst undergraduates at the Rivers State University'.

\section{Methodology}

\subsection{Study Design}

A cross-sectional descriptive study design was used to assess the awareness and attitude of TB towards knowledge, awareness and attitude of TB amongst undergraduate students at the Rivers State University.

\subsection{Study Population}

The Rivers State University of Science and Technology (RSUST) Port Harcourt was established in October, 1980 from the Rivers State College of Science and Technology which was itself established in 1972. It is located at NkpoluOroworukwo in Port Harcourt, the capital of Rivers State, Nigeria. It is the first Technological University in Nigeria and the first state owned State University in the Niger Delta region of Nigeria. The motto of the University is "Excellence and Creativity". The University has a staff strength of 1,870 and a student population of 29,939 15000 . The University is ranked as the 16th 12th among 80 other Universities in Nigeria. The language of instruction in the institution is English.

\subsection{The Mandate of the University}

RSU was established to:

- Produce scientific and technical manpower of various levels needed for essential development;

- Produce technical and science teachers for developmental programmes;

- Assist in the industrial and other developmental programmes through consultancy services, special project centres and related activities;

- Encourage the advancement of learning to all persons without distinction or race, creed, sex or political conviction the opportunity of acquiring a higher and liberal education;

- Provide courses of instruction and other facilities for the pursuit of learning in all the faculties and institutes, and to make facilities available on proper terms of such persons as are equipped to benefit from them;

- Encourage and promote scholarship and conduct research in all fields of learning and human endeavour;

- Relate its activities to the social, cultural and economic needs of the people of Nigeria;

- Undertake any other activities appropriate for a University of the highest standard.

\subsection{Faculties/Schools}

The University has seven faculties; Agriculture, Engineering, Environmental Sciences, Law, Management Sciences, Science and Technical and Science Education; and a Postgraduate School.

\subsection{Institutes/Centres/College}

RSU has five Institutes; Institute of Foundation Studies, Pollution Studies, Education, ART, Geosciences and Space Technology. In addition the university has a College of Medical Sciences.

\subsection{Centres}

It has three Centres: Centre for Continuing Education, Centre for Special projects, Information and Communications Technology Centre.

\subsection{Academic Programmes}

The University runs 37 programmes at the undergraduate level, including undergraduate medical students, nurses and 86 at the postgraduate level. 


\subsection{Relocation of RSUST to Greater Port Harcourt City}

The Rivers State Government has concluded plans for the development of a new City called Greater Port Harcourt City to decongest the already over-crowded Port Harcourt. Its development has already commenced and with the new City would be established a new campus where the present Rivers State University of Science and Technology would be relocated to. According to Government's mission statement on this, "The new University will be a leading Centre of academic excellence in Africa and beyond; a world class University with world-class facilities, which will be manned by a team of committed administrators, academics and researcher of high caliber, who share the founding vision of the new University to be ranked among the best 1,000 Universities in the world by 2020. It is hoped that by the time this objective is realized, there is no doubt that RSUST will be equal to none in Nigeria and indeed in Africa. It has a land mass of approximately $28,4283 \mathrm{~m}^{2}$.

\subsection{Sampling Technique}

A simple random sampling technique was used for the study.

\subsection{Sample Size Determination}

Sample size was calculated using 95\% confidence interval (CI), 5\% marginal error (d); P as.

\subsection{Data Collection}

The employment of an adapted structured interviewer administered questionnaires were used for data collection. The instrument for data collection included socio-demographic characteristics, knowledge/awareness of TB and the TB prevention.

Two research assistants from the College of Medical Sciences of the University were trained on the content and method of administration of the questionnaires prior to the commencement of the study by the research team.

\section{Results}

Three hundred and eleven respondents participated in the study. There were 186 (60\%) males and 125 (40\%) females. The mean age was 24years; 285(91.6\%) were aware of TB; 251(80.7\%) of relations of respondents had open TB of which $40(12.9 \%)$ were treated; $36(11.5 \%)$ had contact tracing for TB, while 172 (55.3\%) were aware of Direct Observe Therapy for the treatment of TB.

Table 1 Age distribution of undergraduates

\begin{tabular}{|l|c|c|}
\hline Variable & Frequency & Percentage \\
\hline Age \\
\hline$<15$ & 2 & 0.6 \\
\hline $15-19$ & 96 & 30.9 \\
\hline $20-24$ & 149 & 47.9 \\
\hline $25-29$ & 57 & 18.3 \\
\hline$\geq 30$ & 7 & 2.3 \\
\hline Total & 311 & 100 \\
\hline Mean & 21.63 SD 3.48 & \\
\hline
\end{tabular}

Table 2 Awareness of TB Amongst Undergraduates

\begin{tabular}{|c|c|c|c|c|c|}
\hline \multicolumn{2}{|c|}{} & Frequency & Percent & Valid Percent & Cumulative Percent \\
\hline \multirow{3}{*}{ Valid } & no & 26 & 8.4 & 8.4 & 8.4 \\
\cline { 2 - 6 } & yes & 285 & 91.6 & 91.6 & 100.0 \\
\cline { 2 - 6 } & Total & 311 & 100.0 & 100.0 & \\
\hline
\end{tabular}




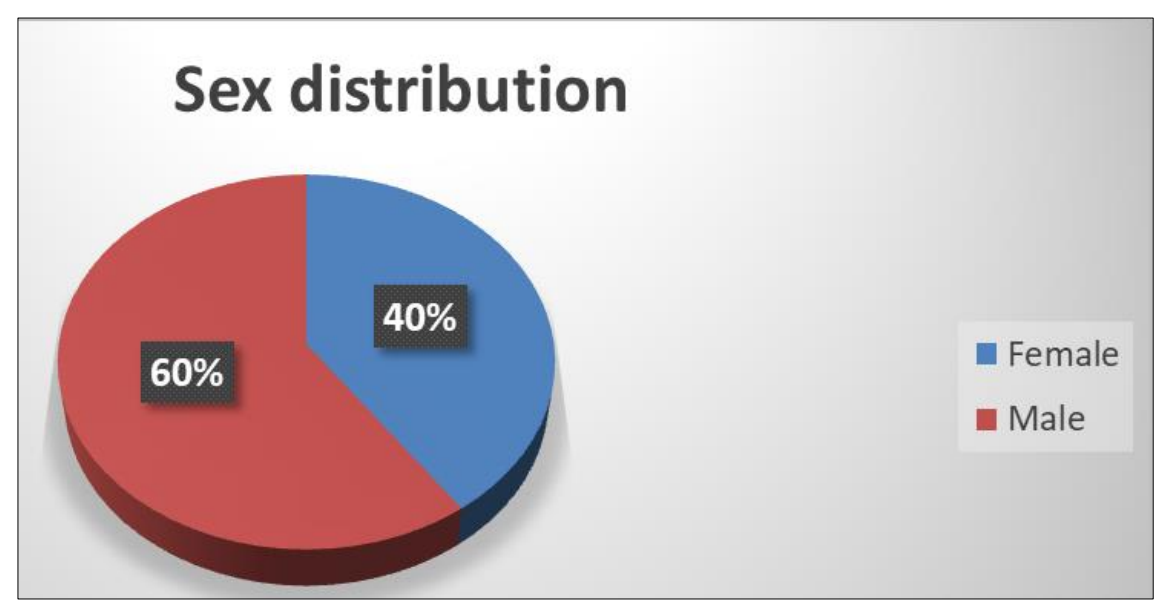

Figure 1 Sex distribution of undergraduates

Table 3 Awareness of direct observe treatment (DOT) by Undergraduates

\begin{tabular}{|c|c|c|c|c|c|}
\hline \multicolumn{2}{|c|}{} & Frequency & Percent & Valid Percent & Cumulative Percent \\
\hline \multirow{3}{*}{ Valid } & no & 139 & 44.7 & 44.7 & 44.7 \\
\cline { 2 - 6 } & yes & 172 & 55.3 & 55.3 & 100.0 \\
\cline { 2 - 6 } & Total & 311 & 100.0 & 100.0 & \\
\hline
\end{tabular}

Table $3 \mathbf{b}$ Undergraduates have a role in prevention of TB/covid-19

\begin{tabular}{|c|c|c|c|c|c|}
\hline \multicolumn{2}{|c|}{} & Frequency & Percent & Valid Percent & Cumulative Percent \\
\hline \multirow{3}{*}{ Valid } & no & 37 & 11.9 & 11.9 & 11.9 \\
\cline { 2 - 6 } & yes & 274 & 88.1 & 88.1 & 100.0 \\
\cline { 2 - 6 } & Total & 311 & 100.0 & 100.0 & \\
\hline
\end{tabular}

Table 4aFriends/relatives of undergraduates infected with TB

\begin{tabular}{|c|l|c|c|c|c|}
\hline \multicolumn{2}{|c|}{} & Frequency & Percent & Valid Percent & Cumulative Percent \\
\hline \multirow{3}{*}{ Valid } & & 1 & .3 & .3 & .3 \\
\cline { 2 - 6 } & no & 251 & 80.7 & 80.7 & 81.0 \\
\cline { 2 - 6 } & yes & 59 & 19.0 & 19.0 & 100.0 \\
\cline { 2 - 6 } & Total & 311 & 100.0 & 100.0 & \\
\hline
\end{tabular}

Table $\mathbf{4 b}$ Those infected that were treated for TB

\begin{tabular}{|c|c|c|c|c|c|}
\hline \multicolumn{2}{|c|}{} & Frequency & Percent & Valid Percent & Cumulative Percent \\
\hline \multirow{3}{*}{ Valid } & no & 271 & 87.1 & 87.1 & 87.1 \\
\cline { 2 - 6 } & yes & 40 & 12.9 & 12.9 & 100.0 \\
\cline { 2 - 6 } & Total & 311 & 100.0 & 100.0 & \\
\hline
\end{tabular}


Table 5 Those treated who had contact tracing for TB

\begin{tabular}{|c|c|c|c|c|c|}
\hline \multicolumn{2}{|c|}{} & Frequency & Percent & Valid Percent & Cumulative Percent \\
\hline \multirow{3}{*}{ Valid } & no & 275 & 88.4 & 88.4 & 88.4 \\
\cline { 2 - 6 } & yes & 36 & 11.6 & 11.6 & 100.0 \\
\cline { 2 - 6 } & Total & 311 & 100.0 & 100.0 & \\
\hline
\end{tabular}

Table 6 Those who had of drugs resistant TB

\begin{tabular}{|c|l|c|c|c|c|}
\hline \multicolumn{2}{|c|}{} & Frequency & Percent & Valid Percent & Cumulative Percent \\
\hline \multirow{3}{*}{ Valid } & no & 135 & 43.4 & 43.4 & 43.4 \\
\cline { 2 - 6 } & yes & 176 & 56.6 & 56.6 & 100.0 \\
\cline { 2 - 6 } & Total & 311 & 100.0 & 100.0 & \\
\hline
\end{tabular}

\section{Discussion}

The study revealed awareness of TB at the Rivers State University (RSU) as $91.6 \%$ which was high, this was little lower than the study done at Benue State University where the level of awareness of TB was 93.8\%. this was similar to studies done in Lagos, Nigeria and India [1,7,8]. The study awareness was notin agreement with the studies done in North Eastern Libya where the level of awareness was lower than that of our study [2]. Further more the level of TB awareness was $27.1 \%$ in a study conducted among students in Sudan [11].The knowledge of TB at the RSU could be attributed to the continuous health talk on TB prevention both physically in the University, the media houses and also in the various social media handles [3,4]. Our study revealed the modal age range was between 20 and 24 years as shown in table 1. This was in agreement with the study done at Ehiopia by Mekonnen et al [10]. There were more male undergraduate respondents from our study compared to females as shown in the pie-chart represented by $60 \%$ and $40 \%$ respectively. This was also in agreement with the Ethiopian study.10 However, the study done in Sudan by Khalid FA was not in agreement with our study as there were more female (53.2\%) students respondents compared to their males counterparts which were $48.8 \%$ of the respondents [11].

Over $50 \%$ of the respondents believed that enough role is not been played by undergraduates in TB prevention. This is in agreement with the study done by Nwaokoro JC in Anambra State; Nigeria [6]. Good number of the respondents in the population did not have knowledge of direct observe therapy (DOT) in TB prevention adopted in Nigeria in 1993 which was implemented across the 36 States and FCT of the country. Despite the implementation of DOT, accessibility by patients still is very poor as most of the inhabitants live far distance from established DOT centres [6]. It is even more challenging and disheartening that less than $50 \%$ of undergraduates are not aware of DOT from our study. All these put together has constrained the attainment of the natural target of TB case treatment success rates [6].

Furthermore, increasing the awareness of TB and its treatment in the community and making the DOT services more accessible and acceptable with public health centres as focal points of health institutions will go a long way of reducing the prevalence of TB in the country $[3,4]$.

With the emerging of Covid-19 pandemic; TB remains a worldwide challenge of public health importance. Furthermore, Nigeria is among the TB ravaged countries of the world [1,3-6].The awareness of TB and preventive modalities and treatment modalities amongst undergraduates cannot be over emphasized in controlling the disease. The university which is a citadel of learning is a citadel of learning is a good ground to disseminate information on TB prevention especially amongst undergraduates who form the good majority of the university population.

\section{Conclusion}

The attainment of the national and global targets will be a possibility if researchers have shown that health education and health promotion as a continuous process should be enhanced; referring to our study which revealed that even though the awareness of TB was over $90 \%$ among undergraduates at the Rivers State University, Nigeria. However, 
relatives of undergraduates who had treatment for TB was poor, representing $12 \%$ of respondents while $11 \%$ had contact tracing. In addition, undergraduates whose relatives had TB should be motivated to seek treatment.

\section{Compliance with ethical standards}

\section{Acknowledgments}

Provost College of Medical Sciences Rivers State University.

\section{Disclosure of conflict of interest}

There was no conflict of interest.

\section{Statement of ethical approval}

The permission for the study was granted by the office of the Provost of the College of Medical Sciences of the Rivers State University. Verbal informed consent was obtained from the respondents.

\section{Statement of informed consent}

Informed consent was obtained from all individual participants of the study.

\section{Funding}

Nil

\section{References}

[1] Ogbeyi GO, Chikaike O, Saliu I, Ijedigbo A. Factors in Tuberculosis Prevention among Students of Benue State University, Makurdi, North Central Nigeria. The Nigerian Health Journal. 2020; 20(2): 54-64.

[2] World Health Organization: Tuberculosis. Fact sheet number 104 Revised. WHO.

[3] Federal Ministry of Health: Nigeria Tuberculosis. Fact sheet; FMOH. March 2017.

[4] Rivers State University https://www.41cu.org.reviews (accesed 1/10/2021).

[5] Nwaokoro JC, Dozie IJ, Nwaokoro AA, Onwuliri VA, Akubue N. Awareness of the prevalence of Tuberculosis in Anambra West Local Government Area, Anambra State, Nigeria. International Journals of Scientific Research. 2019; 8(2): $18-22$.

[6] Mushtag et al in tuberculosis. 2020.

[7] Anochie PC, Onyeneke EC, Ogu AC. Recent advances in mycobacterium tuberculosis. GERMS. 2012; 2:110-20.

[8] Mushtag MU et al Urban - rural inequalities in Knowledge, Attitudes and Practices Regarding Tuberculosis in Two Districts of Pakistani's Purijab Provinces. International Journals for Equity in Health. 2011; 10(1):8.

[9] Bavejasm, Dalal PJ. Awareness of the Revised National Tuberculosis Control ProgrammeandAttitude to Tuberculosis Patients amongst Medical Undergraduates. J Accad Med Sci. 2012; 2:68-72.

[10] Mekonnen A, et al. Tuberculosis, knowledge and attitude among non-health science university students needs attention: a cross-sectional study in three Ethiopian universities. BMC Public Health. 2020; 20: 631.

[11] Khalid FA. Knowledge and awareness of Tuberculosis among Students of University of Kassala, Sudan. Sudan Journal of Medical Sciences. 2013; 8:1. 